\title{
STUDIES ON THE PHYSIOLOGY OF RESPIRATION IN PREGNANCY. EFFECTS OF BARBITURATES ADMINISTERED DURING LABOR ${ }^{1}$
}

\author{
By CHARLES P. SHELDON \\ (From the Department of Obstetrics, Harvard Medical School, and the Boston Lying-in \\ Hospital, Boston)
}

(Received for publication August 5, 1938)

It is becoming increasingly evident that there are certain dangers associated with obstetrical analgesia. Montgomery (1) investigated maternal mortality in Philadelphia and concluded that pentobarbital sodium was a significant factor. Gruber (2) emphasizes the dangers associated with anesthetic doses of the barbiturates, i.e., depression of the cardiorespiratory mechanism and diminution of tonus in smooth muscle (bladder, ureter, and uterus). Acute pulmonary edema may result from toxic doses or even therapeutic doses in individuals with an idiosyncrasy. Henderson (3) considers all narcotics and hypnotics used to produce obstetrical analgesia respiratory depressants, affecting the baby more than the mother. The barbiturates are particularly dangerous because of the diminution of sensitivity to the normal respiratory stimulus-carbon dioxide. $\mathrm{He}$ believes they can be administered safely only in doses large enough to relieve anxiety.

This study was initiated as an attempt to determine the effects of the barbiturates on the respiratory mechanism of the normal parturient woman. It includes the following lines of investigation: (1) lung volume; (2) x-ray mensuration of diaphragm levels; (3) external measurements of the chest; and (4) intra-abdominal pressure.

LUNG VOLUME

Lung volume is an indicator of the functional status of the cardiorespiratory mechanism. Vital capacity has been utilized as an index of lung volume and variable results have been obtained. Alward (4) found a gradual reduction of vital capacity in the last month of pregnancy, a sharp reduction following delivery, and a gradual return to normal limits by the tenth postpartum day. Landt and Benjamin (5) found no signifi-

1 This study was carried out under Grant 424 of the Committee on Scientific Research of the American Medical Association. cant trend during the course of pregnancy although there was a monthly variation of 100 to $300 \mathrm{cc}$. from the mean. This was considered to be within normal limits. Thomson and Cohen (6) report a slight but usually progressive increase before delivery which could be correlated with a widening of the subcostal angle and was thought to be a direct result of mechanical alterations of thoracic volume. Vital capacity represents only one portion of the total lung volume and does not necessarily reflect similar changes in the other components (Figure 1). Christie (7) has devised a technique whereby all of the components of lung volume can be determined. A presentation of the following material will be simplified by definitions taken from Christie's paper.

$V$ ital capacity is the volume of air that can be forced out of the lungs by maximum expiration following the fullest inspiration.

Tidal air is the volume of air expired by a breath of average size.

Subtidal air is the volume of air remaining in the lungs after a normal expiration.

Residual air is the volume of air remaining in the lungs following maximum expiration.

Complemental air is the amount of air inspired from the height of a normal inspiration to maximum inflation.

Reserve air is the volume of air expired from a normal expiration to maximum deflation.

Total capacity is the sum of vital capacity and residual air.

\section{PROCEDURE}

Complete lung volume studies were made on seventeen patients who were delivered on the obstetrical service of the Albany Hospital. The determination of the subtidal air, using Christie's technique, was made with the patient in a supine position, the arms resting at the sides, and the head supported by one pillow. Care was taken to prevent heavy bed clothing from resting upon the abdomen or chest. Binders were unpinned. Vital capacity studies were then performed with the patient in the same carefully controlled position. The complementary and supplementary (reserve air) volumes were computed from the vital capacity. Residual air was determined by sub- 


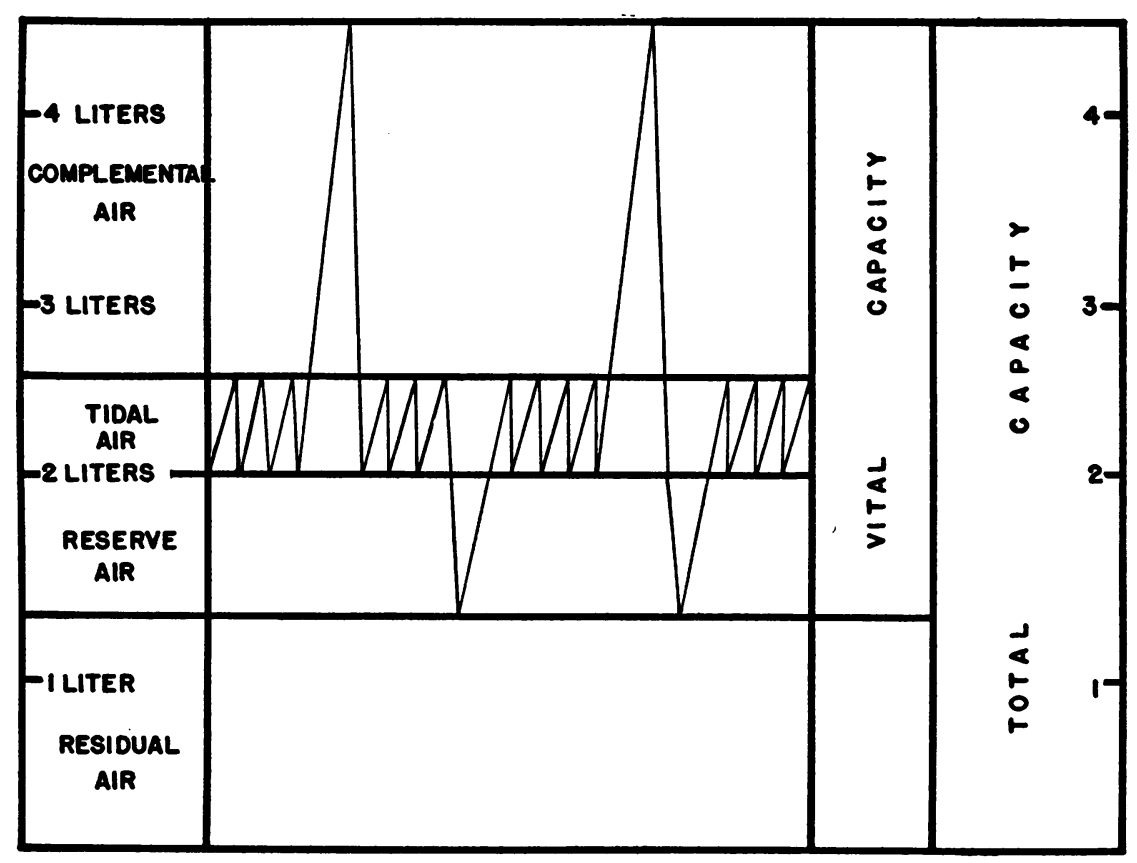

Fig. 1. Lung Volume and its Subdivisions

Total lung volume and its subdivisions are expressed in liters. Absolute values are taken from Hurtado et al. (15).

tracting the reserve air from the subtidal air. Patients were examined under basal conditions insofar as possible. Determinations were made before delivery and at varying stages of the puerperium. The first three days after delivery were investigated more intensely than other stages of the postpartum period because maximum changes occur soon after delivery. Results were expressed in terms of percentage of normal lung volume which was arbitrarily taken, because of Alward's findings, as that found on the tenth postpartum day. Duplicate analyses were always obtained. All volumes were corrected to $37^{\circ} \mathrm{C}$. saturated with water vapor.

Sixteen patients of the series investigated were delivered through the pelvis. This group can be divided into the following sub-groups: $(a)$ four patients were delivered without analgesia or anesthesia; $(b)$ eight patients were given one of the barbiturates and scopolamine during labor and ether anesthesia at delivery; $(c)$ two patients were given one of the barbiturates and scopolamine during labor but no anesthesia at delivery; and (d) two patients had no analgesic drugs during labor but were given ether anesthesia at delivery. The barbiturates administered during labor were seconal, sodium amytal, and pentobarbital sodium. Twelve grains of sodium amytal was the largest dosage used. There was a single patient delivered by cesarean section. Atropine grains $1 / 150$ was given preoperatively and gas-oxygenether was used as the anesthetic.

\section{RESULTS}

The total lung volume shows no significant change although the vital capacity tends to increase slightly in the latter part of pregnancy. The average value for all vital capacity determinations made during the last month of pregnancy was seven per cent above normal in this series (Figure 2).

Patients delivered without analgesia or anesthesia showed either no significant changes or an increase of the total lung volume and its components during the first week following delivery.

Barbiturate and scopolamine analgesia during labor plus ether anesthesia at delivery results in an eight to ten per cent reduction of total volume, functional residual air (subtidal air) and vital capacity as late as the fourth and fifth days of the puerperium. The reduction of vital capacity is actually fifteen to twenty per cent below the antepartum level. The reduction of lung volume is even more striking in the first twenty-four hours after delivery when depression is maximum.

Barbiturates alone decreased the total volume 


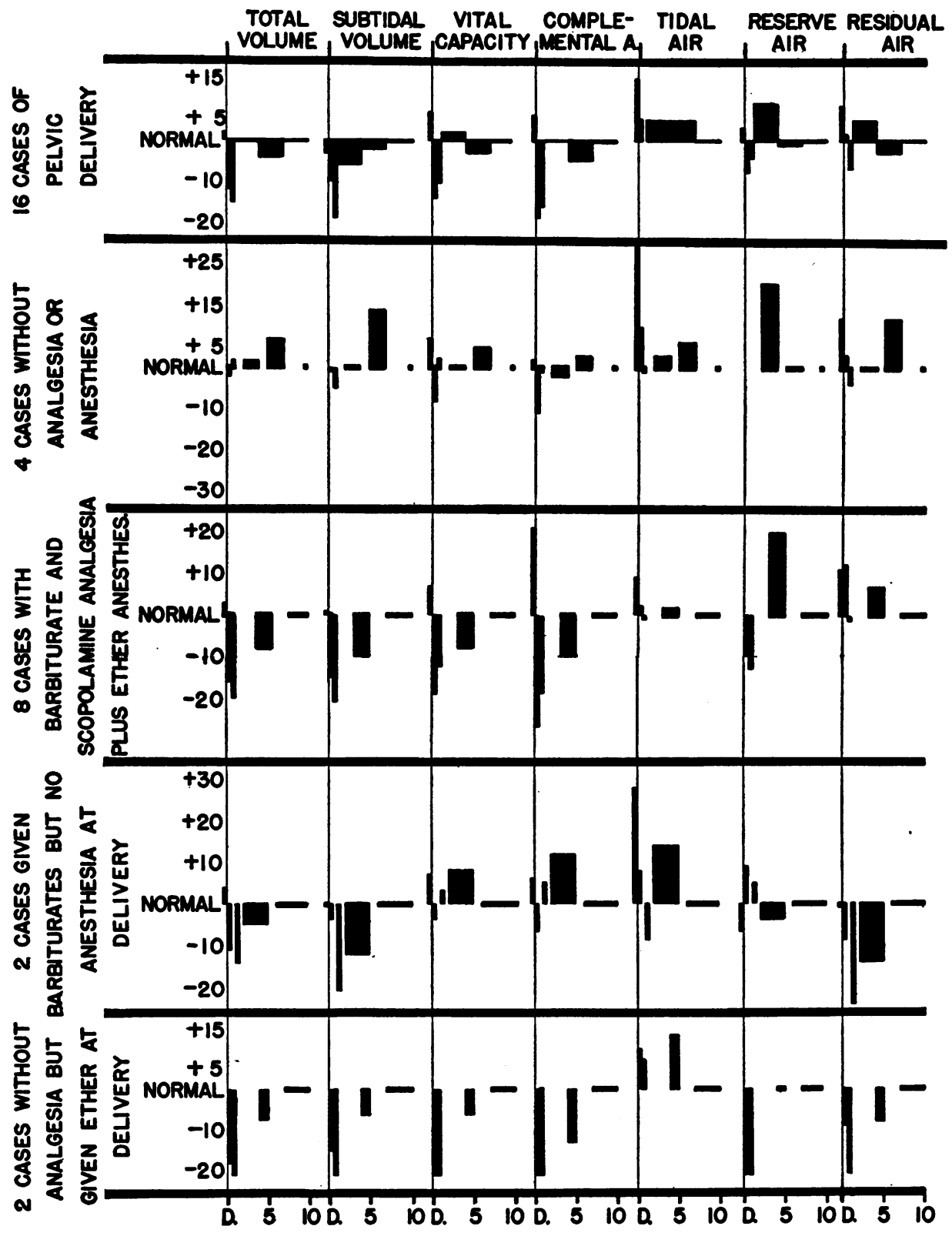

Fig. 2. The Effect of Obstetrical Analgesia on Lung Volume

Vertical lines designated as " $D$ " represent delivery of the patient. The total lung volume and its components have been expressed in terms of percentage of normal which was taken arbitrarily as that value obtained on the tenth postpartum day.

and the subtidal air but the vital capacity remained unaffected.

Ether anesthesia alone decreased the total volume, subtidal air, and vital capacity, but the reduction was less than that brought about by a combination of analgesia and anesthesia.
The patient delivered by cesarean section showed a marked reduction of vital capacity following delivery with a proportionately smaller reduction of total volume. These results indicate the effects of postoperative pain and posture associated with laparotomy. 
Cesarean section reduced the vital capacity markedly. On the other hand, the functional residual air (subtidal volume) increased. An increase of the residual air, which is one of the components of the subtidal volume, compensated for the reduction of vital capacity. The total lung volume therefore was not diminished as much as the vital capacity (Table I).

TABLE I

The effect of cesarean section on lung volume and its components

\begin{tabular}{|c|c|c|c|c|c|c|c|}
\hline Stage & $\begin{array}{l}\text { Total } \\
\text { vol- } \\
\text { ume }\end{array}$ & $\begin{array}{l}\text { Sub- } \\
\text { tidal } \\
\text { vol- } \\
\text { ume }\end{array}$ & $\begin{array}{l}\text { Vital } \\
\text { capac } \\
\text { ity }\end{array}$ & $\begin{array}{l}\text { Com- } \\
\text { ple- } \\
\text { mental } \\
\text { air }\end{array}$ & $\begin{array}{c}\text { Tidal } \\
\text { air }\end{array}$ & $\begin{array}{l}\text { Supple- } \\
\text { mental } \\
\text { air }\end{array}$ & $\begin{array}{l}\text { Re- } \\
\text { sidual } \\
\text { air }\end{array}$ \\
\hline & & $c c$. & & $\begin{array}{c}c c . \\
2273\end{array}$ & $\begin{array}{c}c c . \\
543\end{array}$ & $\begin{array}{l}c c . \\
213\end{array}$ & $c c$. \\
\hline $\begin{array}{l}\text { ostpa } \\
7 \text { ho }\end{array}$ & 3426 & 2537 & 974 & 444 & 445 & 85 & 2452 \\
\hline $\begin{array}{r}\text { Postpa } \\
3 \text { da }\end{array}$ & 4706 & 2915 & 1949 & 1429 & 372 & 175 & 2740 \\
\hline $\begin{array}{l}\text { Postpa } \\
6 \text { da }\end{array}$ & 4211 & & 1973 & 1432 & 308 & 233 & 2238 \\
\hline $\begin{array}{l}\text { Postpa } \\
12 \mathrm{~d}\end{array}$ & & & 2191 & 1626 & 347 & 217 & \\
\hline Postpartu & & & & & & & \\
\hline Post & 404 & 2156 & 2659 & 1967 & 281 & 411 & 1745 \\
\hline & 5015 & 2486 & 2897 & 2226 & 303 & 368 & 2118 \\
\hline
\end{tabular}

\section{External measurements of the chest}

Since the lungs are encased in a bony cagethe thorax-some light may be thrown on the physiology of respiration during pregnancy and the puerperium by measurements of the size of the chest (Figure 3 ). The external measurements have been expressed in terms of percentage of normal. The values for circumference and diameter found on the tenth postpartum day were taken as normals. Measurements were made at the level of the submammary crease.

The anteroposterior diameter of the chest was fifteen to twenty per cent above normal during the last two weeks of pregnancy. The circumference was increased approximately ten per cent. We have seen that total lung volume remains essentially unchanged during pregnancy in spite of an apparent increase in the size of the thoracic cavity. Flaring of the ribs may therefore be a mechanical factor which compensates for a cephalic displacement of the diaphragm by the advancing pregnancy.

\section{$X$-ray mensuration of diaphragm levels}

Landt and Benjamin (5) have observed elevation of the diaphragm from the fourth month on. By the middle of pregnancy the elevation averaged two centimeters above normal at the end of deep inspiration. McGintry (8) found higher diaphragm levels and a greater excursion antepartum than postpartum. Lewis (9) has demonstrated experimentally the importance of activity of the diaphragm in maintaining the normal relationship between intra-abdominal and intrathoracic pressures.

Immediately following delivery a descent of the diaphragm occurs which is of great importance as this increases intra-abdominal pressure and restores a normal balance. Case 1 delivered without analgesia or anesthesia demonstrated a

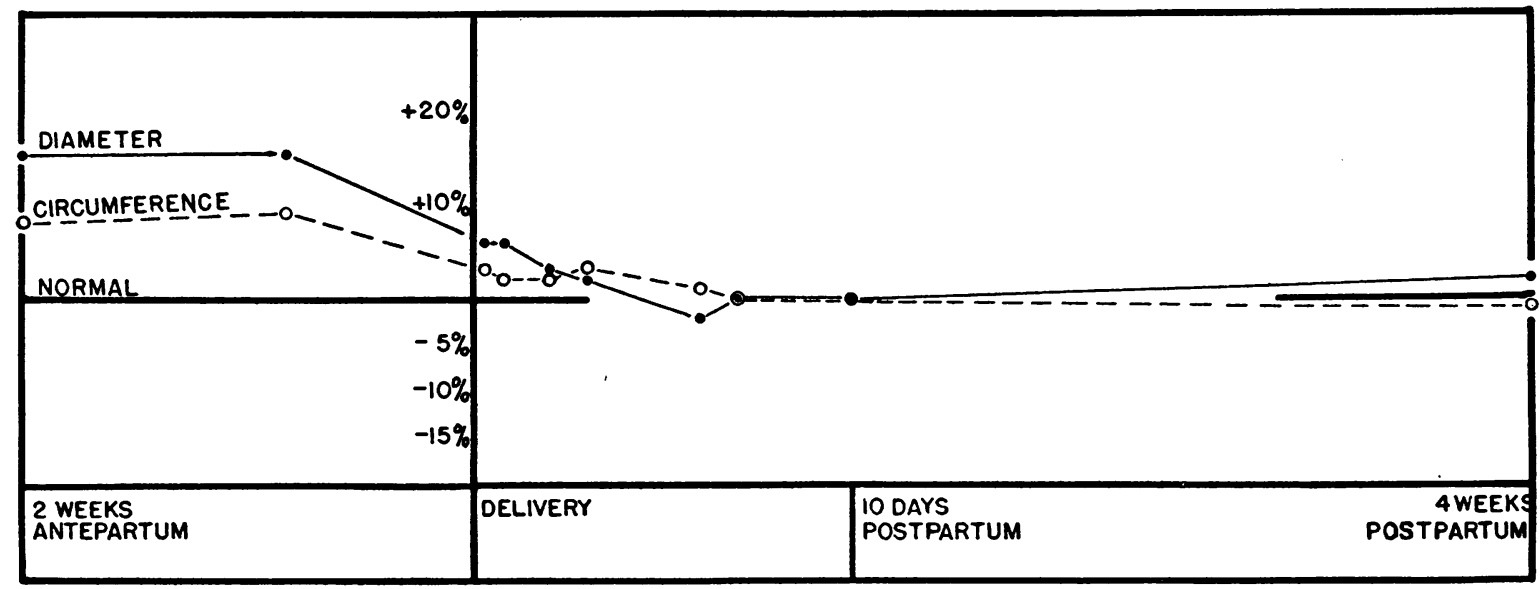

Fig. 3. External Measurements of the Chest 


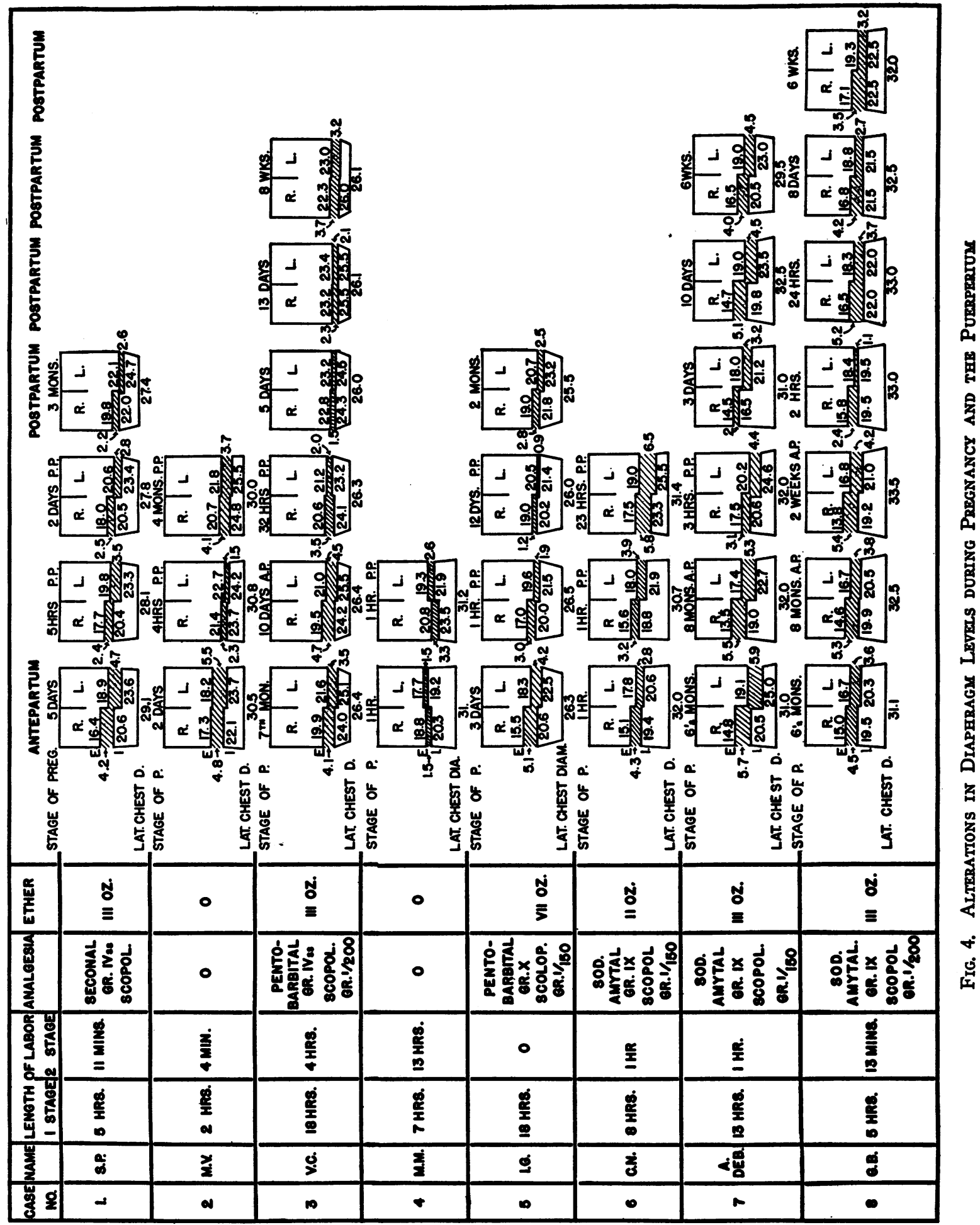


descent of the diaphragm measuring $1.6 \mathrm{~cm}$. four hours after delivery. Case 4 similarly delivered showed a descent of $3.2 \mathrm{~cm}$. one hour after delivery. Descent of the diaphragm was retarded by the depression associated with analgesic drugs during labor and anesthesia at delivery.

Figure 4 illustrates the alterations in diaphragm levels during pregnancy and the puerperium. Roentgenograms were taken at the end of maximum inflation and maximum deflation. The first three cases were $\mathrm{x}$-rayed at 84 inches with the patient always in a sitting position. The remainder were $\mathrm{x}$-rayed in a supine position with the distance from target of the Coolidge tube to the plate kept constant at 30 inches. Measurements were made from the first rib to the dome of the diaphragm and are expressed in centimeters. " $E$ " represents expiration and " $I$ " inspiration. The cross-hatched area represents the excursion of the diaphragm.

\section{Intra-abdominal pressure}

Coombs (10) considers the intra-abdominal pressure lower during pregnancy than under normal conditions in spite of an increase in the contents of the abdominal cavity. Schatz (11) suggests that there is an adjustment of the abdominal muscles to compensate for distention of the pregnant uterus. Emerson (12) concludes from animal experimentation that normally intra-abdominal pressure is above atmospheric pressure and fluctuates with the respiratory excursion of the diaphragm and thorax. There is a decrease of intra-abdominal pressure whenever the tone of the diaphragm and abdominal muscles is diminished. Following delivery we have observed a diminished respiratory excursion in spite of the fact that the diaphragm has less resistance to contract against. Due to failure of the abdominal recoil expiration is only partially accomplished.

A bag measuring one and one-half inches in diameter by three inches in length was made of the same non-distensible material as is used in Voorhees' bags. This was attached to a mercury manometer by means of a rigid rubber tube which would transmit pressure changes only in its long axis. The bag was distended with water by means of a burette attached to the upright arm of the manometer. The system was adjusted so that the mercury levels in the U-tube were equal when the bag was at the level of the rectum. The bag was then deflated, inserted into the large bowel and reinflated with an equal quantity of water. Pressures were expressed in millimeters of mercury.

Intrarectal pressure readings were performed on five patients in an attempt to ascertain indirectly the changes in intra-abdominal pressure which follow delivery (Table II). There was

TABLE II

Intrarectal pressure readings

\begin{tabular}{|c|c|c|c|}
\hline Patient & Stage & $\begin{array}{c}\text { Intra- } \\
\text { rectal } \\
\text { pressure }\end{array}$ & Reduction \\
\hline Mrs. L.... & $\begin{array}{l}\text { Antepartum } \\
1 \text { hour postpartum } \\
1 \text { month postpartum }\end{array}$ & $\begin{array}{c}m m . H g \\
24 \\
12 \\
36\end{array}$ & $\begin{array}{c}\text { per cent } \\
50\end{array}$ \\
\hline Mrs. DeM. . & $\begin{array}{l}\text { Antepartum } \\
1 \text { hour postpartum }\end{array}$ & $\begin{array}{l}22 \\
17\end{array}$ & 77 \\
\hline Mrs. G.. . & $\begin{array}{l}\text { Antepartum } \\
1 \text { hour postpartum } \\
10 \text { days postpartum }\end{array}$ & $\begin{array}{r}17 \\
7 \\
18\end{array}$ & 41 \\
\hline Mrs. F. C.. & $\begin{array}{l}\text { Antepartum } \\
1 \text { hour postpartum }\end{array}$ & $\begin{array}{l}26 \\
20\end{array}$ & 77 \\
\hline Mrs. M. M. & $\begin{array}{l}\text { Antepartum } \\
3 \text { hours postpartum }\end{array}$ & $\begin{array}{l}28 \\
17\end{array}$ & 61 \\
\hline
\end{tabular}

roughly a fifty per cent reduction in intrarectal pressure immediately following delivery. Weisker (13) considers the pressure in hollow viscera to be independent of intra-abdominal pressure because wide variations occur in the contents of the cavity and elasticity of its wall. Nevertheless, it seems reasonable that intra-abdominal pressure should decrease following delivery because of the sudden alteration in the size of the uterus after expulsion of the products of conception thereby decreasing the contents of the abdominal cavity.

\section{DISCUSSION}

Vital capacity is considered a fair index of cardiac and respiratory function. In attempting to measure this component of the total lung volume during pregnancy and the puerperium it is necessary to take into consideration all extraneous factors which may have an effect such as fatigue, posture, sedation, etc. A patient who is given 
no analgesia or anesthesia should not be compared with patients depressed by such measures. From experimental evidence it seems reasonable to assume that after the exclusion of the reduction that results from fatigue of a long labor, which may be negligible, there is no significant change in the vital capacity following pelvic delivery provided labor is conducted without analgesia and delivery is carried out without anesthesia. If, on the other hand, barbiturates and scopolamine are administered during labor and ether is given at delivery, there is a significant reduction of the vital capacity below the antepartum level. If we take into account an abdominal operation such as cesarean section we observe a rather marked reduction of vital capacity but the decrease of total lung volume is proportionately much less.

There would seem to be a mechanism which prevents a serious reduction of the functional residual air (subtidal volume) following delivery, whether pelvic or abdominal in type. A reduction of intra-abdominal pressure after delivery and a subsequent descent of the diaphragm are undoubtedly significant factors. The diaphragm is the most important muscle of respiration since it is the direct expander of the lower lobes. Its position and excursion are closely linked with the relationship between intra-abdominal and intrathoracic pressures. Prinzmetal and Kountz (14) record a moderate rise of the intrapleural pressure late in pregnancy owing to ascent of the diaphragm. Following delivery, the decrease of intra-abdominal pressure is compensated for by descent of the diaphragm which results in a rise of pressure during inspiration. If diaphragmatic activity and descent are diminished by loss of tonus caused by excessive dosage of drugs during labor, this mechanism is disturbed and the intra-abdominal pressure will approach the intrapleural pressure. Efficient respiration depends upon the pressure in the pleural cavity being much more negative than that in the peritoneal cavity. Without this pressure difference elevation of the diaphragm during expiration will be greatly limited. The retardation in descent of the diaphragm in patients given barbiturates during labor permits deflation of the lungs, accumulation of mucus and closure of bronchi. Absorption of air from the occluded areas results in atelectasis. Tonus of the diaphragm and thoracic muscles keeps the lungs and thorax expanded and prevents atelectasis.

\section{CONCLUSIONS}

1. Lung volume determinations, using Christie's technique, were performed on a limited number of puerperal patients. Determinations were made at varying stages of pregnancy and the puerperium.

2. The total lung volume shows no significant alterations as a result of pregnancy.

3. The vital capacity normally increases slightly in the antepartum period. If labor is conducted without analgesia and delivery is performed without anesthesia there is a moderate reduction in this component of the total lung volume following delivery which rapidly returns to normal.

4. Respiratory depression resulting from large doses of analgesic drugs during labor or profound anesthesia at delivery will alter the cardiorespiratory mechanism so that the vital capacity is markedly reduced in the postpartum period and its return to normal is delayed.

5. Cesarean section is accompanied by a marked reduction of vital capacity and a proportionately smaller reduction of total volume.

6. Alterations of thoracic volume from flaring of the costal margins compensates for a cephalic displacement of the diaphragm by the advancing pregnancy. The total lung volume is thereby maintained at approximately its normal level.

7. An increased excursion of the diaphragm as pregnancy advances assists in maintaining normal aeration of the lungs and compensates for any possible atelectasis of the lung bases as a result of compression by the encroaching diaphragm.

8. Descent of the diaphragm following delivery results in a rise of intra-abdominal pressure during inspiration thereby assisting the respiratory mechanism which otherwise would be embarrassed by the reduction of expiration owing to failure of the abdominal recoil. Experimental evidence suggests that diaphragmatic activity and descent are diminished by loss of tonus resulting from excessive dosage of drugs during labor.

9. Barbiturates are respiratory depressants and should not be used in doses that will produce more than a sedative effect during labor. 


\section{BIBLIOGRAPHY}

1. Montgomery, T. L., Obstetric amnesia, analgesia and anesthesia; their relationship to sudden death in labor. J. A. M. A., 1937 108, 1679.

2. Gruber, C. M., Certain pharmacologic actions of the newer barbituric acid compounds. Am. J. Obst. and Gynec., 1937, 33, 729.

3. Henderson, Y., The Pharmacopeia and the physician; respiratory stimulants and their uses. J. A. M. A., 1937, 108, 471.

4. Alward, H. C., Observations on vital capacity during last month of pregnancy and puerperium. Am. J. Obst. and Gynec., 1930, 20, 373.

5. Landt, H., and Benjamin, J. E., Cardiodynamic and electrocardiographic changes in normal pregnancy. Am. Heart J., 1936, 12, 592.

6. Thomson, K. J., and Cohen, M. E., Vital capacity observations in normal pregnant women. Surg. Gynec., and Obst., 1938 66, 591.

7. Christie, R. V., Lung volume and its subdivisions; methods of measurement. J. Clin. Invest., 1932, $11,1099$.

8. McGintry, A. P., The comparative effects of pregnancy and phrenic nerve interruption on the diaphragm and their relation to pulmonary tuberculosis. Am. J. Obst. and Gynec., 1938, 35, 237.

9. Lewis, T., Studies on the relationship between respiration and blood pressure. J. Physiol., 1908, 37, 213.

10. Coombs, H. C., Mechanism of the regulation of intraabdominal pressure. Am. J. Physiol., 1922, 61, 159.

11. Schatz. Quoted by Emerson (12).

12. Emerson, H., Intra-abdominal pressure. Arch. Int. Med., 1911, 7, 754.

13. Weisker. Quoted by Emerson (12).

14. Prinzmetal, M., and Kountz, W. B., Intrapleural pressure in health and disease and its influence on body function. Medicine, 1935, 14, 457.

15. Hurtado, A., Fray, W. W., Kaltreider, N. L., and Brooks, W. D. W., Studies of total pulmonary capacity and its subdivisions; normal values in female subjects. J. Clin. Invest., 1934 13, 169. 